\title{
Optimal foraging: food patch depletion by ruddy ducks
}

\author{
Michael W. Tome* \\ Delta Waterfowl and Wetlands Research Station, R.R. no 1, Portage la Prairie, MB R1N3A1 Canada and \\ School of Natural Resources, The University of Michigan, Ann Arbor, MI 48109, USA
}

\begin{abstract}
Summary. I studied the foraging behavior of ruddy ducks (Oxyura jamaicensis) feeding on patchily distributed prey in a large (5-m long, 2-m wide, and up to 2-m deep) aquarium. The substrate consisted of a $4 \times 4$ array of wooden trays $(1.0-\mathrm{m}$ long, $0.5-\mathrm{m}$ wide, and $0.1-\mathrm{m}$ deep) which contained $6 \mathrm{~cm}$ of sand. Any tray could be removed from the aquarium and "loaded" with a known number of prey. One bird foraged in the aquarium at a time; thus, by removing a food tray after a trial ended and counting the remaining prey, I calculated the number of prey consumed by the bird. I designed several experiments to determine if ruddy ducks abandoned a food patch in a manner consistent with the predictions of a simple, deterministic, patch depletion model. This model is based on the premise that a predator should maximize its rate of net energy intake while foraging. To accomplish this, a predator should only remain in a food patch as long as its rate of energy intake from that patch exceeds the average rate of intake from the environment. In the majority of comparisons, the number of food items consumed by the ruddy ducks in these experiments was consistent with the predictions of the foraging model. When the birds did not forage as predicted by the model, they stayed in the patch longer and consumed more prey than predicted by the model. An examination of the relation between rate of net energy intake and time spent foraging in the food patch indicated that by staying in a patch longer than predicted, the ruddy ducks experienced only a small deviation from maximum rate of net energy intake. These results provided quantitative support for the prediction that ruddy ducks maximize their rate of net energy intake while foraging.
\end{abstract}

Key words: Ruddy ducks - Oxyura jamaicensis - Optimal foraging - Marginal value theorem - Patch depletion

Ruddy ducks (Oxyura jamaicensis) forage by diving beneath the water surface and consuming benthic invertebrates, primarily chironomid larvae (Siegfried 1973; Tome 1981). The birds dive repeatedly in the same area of a wetland until that foraging site is abandoned and then dive less intensively through several other areas until another site is reached where concentrated foraging begins again. The birds repeat

* Current address and address for offprint requests: U.S. Fish and Wildlife Service, Patuxent Wildlife Research Center, Laurel, MD 20708, USA this pattern throughout a foraging bout. These observations, plus the results of prey sampling at ruddy duck foraging sites (Tome 1981), suggest that their foods have a patchy distribution.

Female ruddy ducks must consume between 5000 and 8000 chironomids per hour spent feeding, or $20-40$ chironomids per dive, to meet total daily energy requirements during reproduction (Tome 1981). These results led me to question how ruddy ducks "decide" to leave an exploited patch to begin searching for a new, undepleted patch if they are to successfully locate and consume enough chironomids to meet their energy needs. A method of learning more about the foraging behavior of ruddy ducks is to compare results from experimental trials with those predicted by optimal foraging models.

The question of whether animals exhibit optimal foraging behavior has been disputed by ecologists. Emlen (1966) and MacArthur and Pianka (1966) were first to mathematically model the optimal utilization of food resources by predators. Their papers formed the basis for research about what is generally known as optimal foraging theory. Reviews of the optimal foraging theory literature by Krebs and Cowie (1976), Pyke et al. (1977), Krebs et al. (1983) and Pyke (1984) indicate that most species whose foraging behavior has been analyzed conform closely to the qualitative predictions of optimal foraging models. A major criticism of optimal foraging theory, however, is that few rigorous quantitative studies have tested predictions of the theory (see, however, Cowie 1977; Belovsky 1981, 1984).

One problem faced by many predators is when to leave a food patch and begin searching for a new, undepleted patch. Charnov (1976) developed a model, the marginal value theorem, to predict the optimal time for a predator to leave the patch. Charnov's model predicts that a predator will cease foraging in a patch when its rate of food intake drops below the average rate of intake for the entire environment. The rate of prey intake from a patch may decrease as a result of 1) the predator consuming prey in the patch (exploitation depression), 2) prey fleeing from the foraging area (behavioral depression), or, 3) prey changing their location within the foraging area to decrease their vulnerability (microhabitat depression) (Charnov et al. 1976).

Because ruddy ducks feed on invertebrates distributed in patches that may become depleted, their foraging behavior may be compared with predictions of Charnov's (1976) marginal value theorem. This paper reports on a series of 4 experiments that I designed to determine if ruddy ducks 
exploit food patches in a manner consistent with the predictions of the marginal value theorem.

\section{Methods}

I conducted all experiments within a large, concrete and glass aquarium that was 5-m long, 2-m wide, and 2-m deep. Three $1-\mathrm{m}$ by $1-\mathrm{m}$ glass windows were located on one side and a single $1-\mathrm{m}$ by $1-\mathrm{m}$ window was located on one end. The windows permitted observing and filming of the bird's underwater behavior. The substrate consisted of a $4 \times 4$ array (Fig. 1) of $1.0-\mathrm{m}$ long, $0.5-\mathrm{m}$ wide, and $0.1-\mathrm{m}$ deep wooden trays filled with $6 \mathrm{~cm}$ of sand. The trays could be removed from the aquarium and replaced with trays that had food items hidden in the sand; these trays were food patches in the experiments. Depending on the experiment, 1 or 2 trays were chosen as food patches and contained a specified number of prey. The trays also could be situated at any level in the water column to create different diving depths for the birds.

Six ruddy ducks (4 males, 2 females) were selected randomly from the 45 that were available for the study. They were hatched from eggs collected in the wild and reared in captivity at Delta Waterfowl and Wetlands Research Station, Portage la Prairie, Manitoba, Canada following techniques described by Ward and Batt (1973). First generation hatchery birds were used to minimize experimental bias that could result from observing descendants of birds reared in captivity for many generations. Individuals were named after their leg band colors and will subsequently be referred to as $\mathrm{Al}$ (female aluminum), Blue, Green, Fred (female red), Red, and Yellow. For each experiment, the birds were subjected to the exact experimental procedure for 7 days before I collected data; by doing this I assumed the birds learned the quality (e.g., no. of prey expected, initial encounter rate with prey, etc.) of the food patches available in the experiment.

Although wild ruddy ducks feed primarily on chironomid larvae, I could not obtain adequate numbers of them for my experiments. Consequently, I used wheat grains as prey. Experimental birds had experienced feeding on wheat because it was in their daily maintenance diet. Several times I observed the bird's foraging on both chironomid larvae and wheat grains and they did not exhibit any obvious behavioral differences when consuming the two food types. Between experiments, birds were fed an ad lib. ration of wheat, protein supplement, grit, and vitamins. Food was withheld from the birds for approximately $10 \mathrm{~h}$ before each trial.

The procedure for placing prey in the food patches was the same in all experiments. Before conducting experiments on each day, I counted out the appropriate number of prey to be placed in each food patch for all experiments on that day. Before I placed prey items in the tray, I removed the top $1 \mathrm{~cm}$ of sand. The wheat grains were scattered evenly on the surface of the remaining sand. Sand that had been removed was carefully placed over the prey so that they were not disturbed.

When experiments were not being conducted, an array of empty patches was present in the aquarium. Before each trial, the empty tray in the location designated as a food patch was removed from the aquarium and replaced with one containing food. One bird was allowed to forage in the aquarium until the end of the trial; then, the exploited

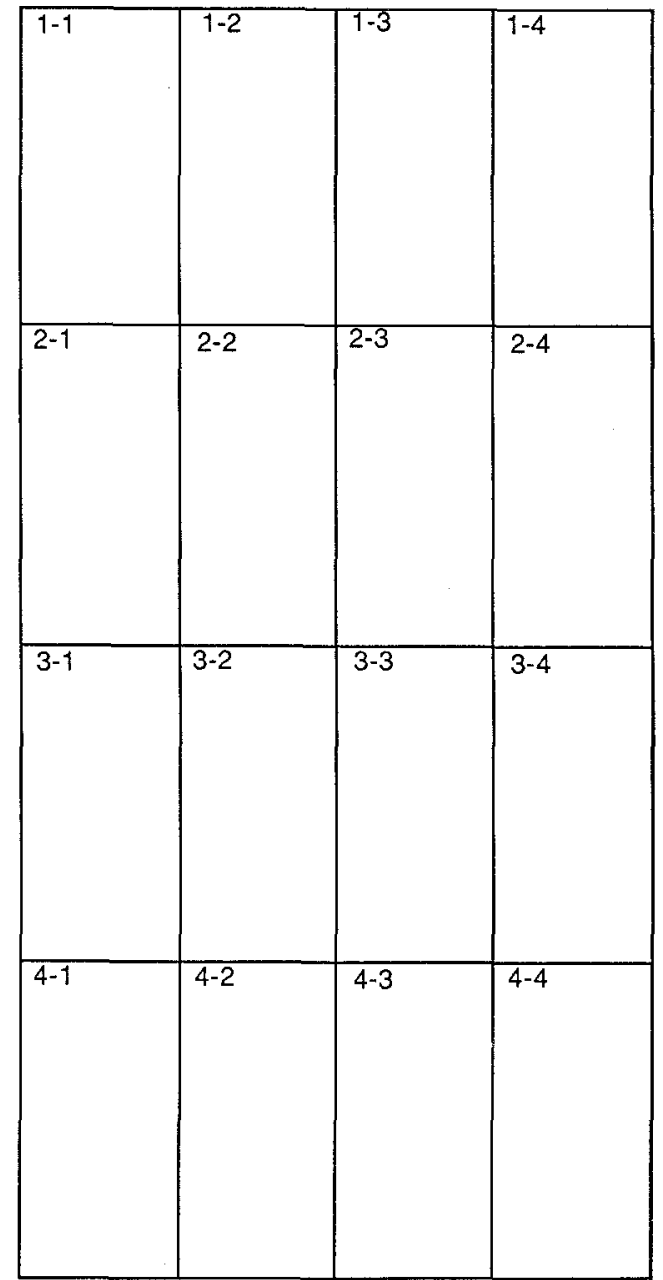

Fig. 1. Diagram of the configuration of trays that comprised the substrate of the foraging environment. Numbers in the upper left hand corner of each tray refer to the tray"s location within the array of trays

food patches were removed and replaced with full food patches. The order of the birds in the foraging trial was chosen randomly each day to avoid biases that could result from duration of pre-experiment food deprivation.

The contents of exploited patches were sieved through a large screen with openings $(0.32 \mathrm{~cm})$ that retained unconsumed wheat. The number of food items consumed by the bird during a foraging bout was then calculated. This procedure was repeated for each food patch visited during a trial.

\section{Experiment 1: Establishing the energy gain function}

I designed this experiment to measure the rate of prey consumption relative to the time spent foraging in the patch. My objectives were to: 1) determine if the rate of energy consumption decreased with time spent in the patch and, 2) define the function (the energy gain curve) that described the rate of energy (prey item) intake by each bird from patches of 2 types (high and low density). The energy gain curve was needed to predict when the bird should abandon a patch and move to an unexploited one.

Water depth was $1 \mathrm{~m}$ and the prey densities were 100 items per tray (200 prey $\mathrm{m}^{-2}$ ) for the first series of 
trials and 150 items per tray $\left(300\right.$ prey $\mathrm{m}^{-2}$ ) for the second series. The food patch was always located in tray 1-2 (Fig. 1) during this experiment; thus, the birds quickly learned the location of and dived directly to the food patch.

A single bird was allowed to forage in the tray for a predetermined time; then, the bird was removed from the aquarium. Ten trials per bird, with foraging times ranging from 5 to $200 \mathrm{~s}$, were conducted at each prey density to determine the shape of each bird's energy gain curve. During a feeding bout, travel time to and from the food patch, feeding time in the patch, and the time spent on the water surface between dives (dive-pause) were measured. The ruddy ducks made several dives to a food patch, resting on the water surface between dives, before the patch was abandoned. The feeding time included only the amount of time the bird actively sieved through the food patch substrate.

A scatter-plot of the cumulative number of food items consumed in relation to the cumulative time spent in the food patch at each density was used to determine if the energy gain function was curvilinear. The function describing the curve was determined from a natural logarithmic transformation of the dependent and independent variables to obtain a linear relationship. Linear regression was employed to determine the energy gain function (Zar 1974). Back transformation of the linear regression results provided a power function equation of the form $Y=a X^{b}$. The slope and intercept of the transformed linear regression equations were compared among birds with analysis of covariance (ANCOVA) ( $\operatorname{Zar} 1974$ ). All tests were considered significant at alpha $\leq 0.05$.

\section{Experiment 2: Optimal patch departure: 1 patch density of known location}

I designed this experiment to determine the relation between the energetic cost of obtaining food from a patch and the number of prey consumed from the patch. A prediction of the marginal value theorem is that the amount of food consumed in a patch will increase as the energy cost of traveling between patches increases (Charnov 1976).

In this experiment, 2 trays were designated as food patches and each contained 150 items ( 300 prey $\mathrm{m}^{-2}$ ) at the beginning of each trial. Food patch locations were constant (Trays 1-2 and 4-2) throughout the experiment. The experiment was divided into three phases; each with a different energy cost of traveling between the food patches. In Phase $\mathrm{A}$, the trays were at a depth of $1 \mathrm{~m}$. In Phase B, the trays were at a depth of $2 \mathrm{~m}$ and a floating, wire-mesh screen with a small opening in the center was placed on the water surface. The test bird had to initiate and end all dives from this opening, which was positioned so that the one-way travel distance to the center of each food patch was $2.3 \mathrm{~m}$. Finally, in Phase C, all trays were kept at $2 \mathrm{~m}$ and energy costs of travel between the food patches were further increased by adding a styrofoam "backpack" to each bird to increase its buoyancy by $10 \%$. Otherwise, the experimental design was the same as in Phase A.

During each phase of this experiment, a trial began with the first dive to one of the food patches. Because the birds were conditioned to the exact experimental procedure for one week before the initiation of the actual experiment, the birds always dived to and foraged within one of the food patches. A trial continued until the bird abandoned the second food patch and began searching for food elsewhere within the array of trays. As soon as this happened, the trial was ended and the two exploited food patches were removed from the aquarium. The remaining food items were counted to determine the number consumed by the birds. During the trial, I recorded the travel time to and from the feeding site, the time spent foraging in each food patch, and the dive-pause times.

Five trials were conducted for each bird in Phases A and $B$ and 10 trials per bird were conducted in Phase $C$. Because 2 patches were exploited in each trial, this provided 10 patch depletion measurements in Phases $A$ and $B$ and 20 measurements in Phase C. I used a $t$-test to compare the average number of food items consumed from a patch with the value predicted by the marginal value theorem.

\section{Experiment 3: Optimal patch departure: 2 patch densities of known location}

I designed this experiment to determine if the foraging birds depleted food patches to the predicted optimal level when the patches in the aquarium environment were of different quality. This design was similar to that of Phase B of Experiment 2 , except that Tray 4-2 contained 150 prey $\left(300 \mathrm{~m}^{-2}\right)$, Tray 1-2 contained 100 prey $\left(200 \mathrm{~m}^{-2}\right)$ and the wire-mesh screen was not placed on the water surface. The criteria ending a foraging trial in Experiment 2 also were used in this experiment. Travel time to and from the feeding site, the time spent foraging in each food patch, and dive-pause time were measured.

Ten trials were conducted for each bird. I used a $t$-test to detect significant differences between the average number of prey consumed from a patch and the number predicted by the marginal value theorem.

\section{Experiment 4: Optimal patch departure from patch of unknown location}

In this experiment, the birds were not conditioned to know the location of the food patch and, consequently, expended time and energy locating it before foraging. Each day, one food patch was randomly located within the array of 16 trays with the restriction that the food tray could not be in the same location on consecutive days. One trial per bird was conducted on each day. Except for the random location of the single food tray, the experimental procedure and variables measured in these trials were the same as in Experiment 3.

Ten foraging trials were conducted for each bird. A $t$-test was employed to detect significant differences between the average number of prey consumed from a patch and the number predicted by the marginal value theorem. Similarly, I used a $t$-test to detect differences between number of prey consumed from patches of known (Experiment 3) and unknown (Experiment 4) location.

\section{The foraging model}

The model I used to predict the optimal level of patch depletion by the ruddy ducks was Charnov's (1976) marginal value theorem. When there is only one patch type, the net energy intake from the patch can be expressed as

$E n=\frac{g(T)-t_{t} * E_{t}}{t+t_{t}}$ 
where:

$E n=$ rate of net energy intake from a patch of food, $g(T)=h(T)-E_{s} * T=$ assimilated energy intake corrected for energy spent by foraging $T$ units of time in the patch, $h(T)=$ assimilated energy from foraging $T$ units of time in the patch (energy gain function),

$T=$ time spent in the food patch, food,

$E_{s}=$ energy expended per unit time while searching for

$E_{t}=$ energy expended per unit time traveling between

patches, and

$t_{\mathrm{t}}=$ time spent traveling between patches.

Ruddy ducks make from 1 to several dives to a food patch before it is abandoned; thus, the within-patch energy and time for traveling between the surface and the patch, and the time spent on the water surface between withinpatch dives must be incorporated in the model to calculate the rate of net energy intake from foraging $T$ units of time.

The modified model is:

$E n=$

$\frac{h\left(T_{f}\right)-E_{d}\left(T_{f}+a * T_{f}\right)-E_{d p}\left(b * T_{f}\right)-\left(E_{d} * t_{t}\right)-\left(E_{d p} * t_{d p}\right),}{t_{t}+t_{d p}+T_{f}(1+a+b)}$

where:

$T_{f}=$ total time spent searching in a food patch,

$\mathrm{E}_{d}=$ energy cost per unit time while diving,

$E_{d p}=$ energy cost per unit time while sitting on the water surface between dives,

$t_{d p}=$ time spent on the water surface when traveling between food patches (dive-pause),

$t_{t}=$ time spent traveling between food patches, exclusive of $t_{d p}$,

$a=$ ratio of round trip travel time between a food patch and the surface to the average time spent foraging in a patch during a single dive, [thus, $\left(a * T_{f}\right)$ is an estimate of the total time spent traveling during within-patch foraging dives], and,

$b=$ ratio of time spent on the surface during foraging dives to the average time spent foraging in a patch during a single dive [thus, $\left(b * T_{f}\right)$ is an estimate of the total time spent on the water surface between within-patch foraging dives].

I designed the model so that the time and energy spent traveling to a food patch the first time, and the time and energy spent returning to the water surface and on the surface after the patch had been abandoned, were considered as $t_{t}$ and $t_{d p}$.

All values for the above variables were either derived from the literature or determined from the experiments. The energy gain function, $h(T)$, was derived from Experiment 1. One grain of wheat was estimated to contain 190 calories (Tome, unpubl. data), of which ruddy ducks could assimilate 150 calories, based on an assimilation efficiency of 0.77 (Brody 1945). The energy cost of diving, $E_{s}$ (3.2 calories/second) and of dive-pause, $E_{d p}(2.5$ calories/ second), were derived from Woakes and Butler (1983). $T_{f}$, $t_{t}, t_{\mathrm{d} p}, a$, and $b$ were determined empirically for each bird.

The optimal solution to Eq. (2) with a single patch type was found by setting the partial derivative of $E n$ with respect to $T$ equal to $O$ and solving for $T$. It was slightly more difficult to determine the optimal level of patch depletion when patches of 2 different densities were in the foraging environment (Experiment 3). A prediction of the marginal value theorem is that the instantaneous rate of energy intake will be constant across all patch densities within an environment when a predator abandons a food patch (Charnov 1976). To solve for the optimal level of patch depletion in Experiment 3, I calculated the rate of net energy intake for progressively longer times in the 2 patch environment when the instantaneous rate of energy intake was equal in each patch at the time the predator abandoned the patch. As the total foraging time in the environment increased, the rate of net energy intake increased to a maximum and then decreased as the patch was exploited past the optimum. The maximum rate of net energy intake obtained from these calculations provided the optimal solution for a multiple density environment. Because there is variation in several of the measurements used to calculate the predicted values, there is also variation associated with the optimal solution of the marginal value theorem equation. I used 500 simulations of the bootstrap procedure (Efron and Gong 1983) to calculate the standard error of each predicted value.

Several assumptions must be satisfied before this variation of Charnov's (1976) marginal value theorem may be applied to a foraging situation. First, the predator's rate of energy intake must decrease with time spent in the patch. Experiment 1 was designed to show that this assumption was met. Secondly, the predator must know the quality of the patch before it is entered (i.e., the predator is omniscient). By conducting 7 trials before collecting data in each experiment, I assumed that the birds learned the quality of patches that were available. Thirdly, there should be a limitless number of patches available for the birds to exploit so that the birds do not revisit food patches and so the average travel time between unexploited patches does not increase. In my experiments there were a limited number of food patches ( 1 or 2); however, I ended each trial before the birds revisited food patches. In addition, the birds new the food patch location (except in Experiment 3) and dived directly to each food patch, thus satisfying the constant travel time between patches assumption. In Experiment 3, the average time required to find a food patch was used as an estimate of the average travel time between food patches. I assumed that the ruddy ducks exploited the aquarium environment the same as an environment with an unlimited number of food patches. Finally, I assumed that the predators attempted to maximize their rate of net energy intake and that there was a positive correlation rate of net energy intake and reproductive fitness.

The marginal value theorem predicts the optimal time a predator should forage in a given type of patch. Because of the deterministic relationship between time in the patch and number of prey consumed from the patch (calculated from the energy gain function determined in Experiment 1), the optimal number of prey consumed from each patch type also was predicted. In this paper, the experimental results and optimal solutions are expressed in terms of number of prey consumed.

\section{Results}

\section{Experiment 1: Establishing the energy gain function}

All birds exhibited energy gain functions that appeared to increase at a decreasing rate. I compared the slopes and intercepts of the energy gain functions among individual birds within a patch density and found no difference in 
the intercepts (density $=150$ prey/tray: $F=1.3113, P=0.27$; density $=100 \mathrm{prey} /$ tray: $F=0.9269, P=0.47)$ or slopes (density $=150$ prey $/$ tray: $F=1.6125 ; P=0.17 ;$ density $=$ 100 prey/tray: $F=1.9068, P=0.11)$. Consequently, the data were combined to obtain a single equation that described the energy gain function for all birds at each density (Fig. 2). When back-transformed, these equations were:

$h(T)=2.43 * T^{0.64}$

$\left(n=55 ; r^{2}=0.80 ; P<0.0001\right)$

for patches with 100 prey, and,

$h(T)=3.66 * T^{0.67}$

$\left(n=61 ; r^{2}=0.93 ; P<0.0001\right)$,

for patches with 150 prey,

where

$T=$ time in the food patch.

The slopes and intercepts of these equations were compared using the transformed data. The intercepts of the
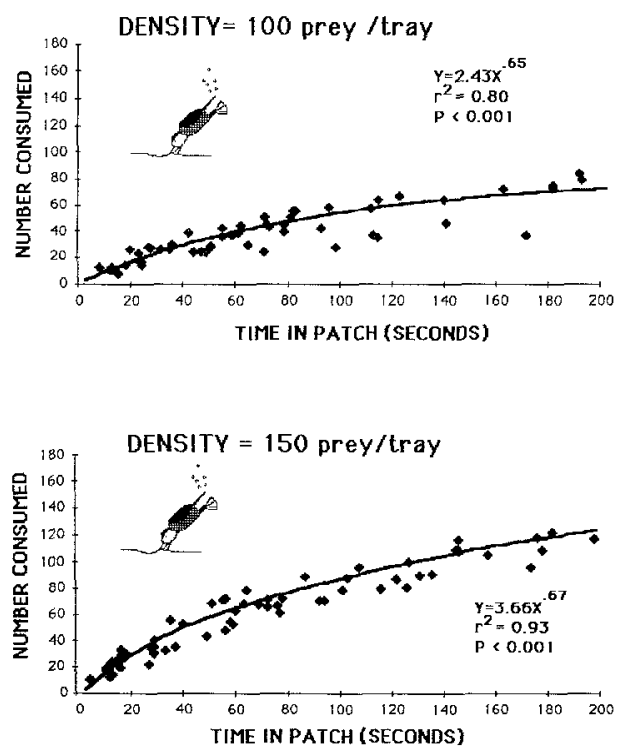

Fig. 2. The regression equations explaining the relation between the cumulative number of prey consumed with time spent foraging in patches containing densities of 100 and 150 prey per tray. Data are for all birds combined transformed equations differed significantly $(F=143.96$; $P<0.001)$; however, the slopes did not $(F=0.22047 ; P=$ $0.6396)$.

Experiment 2: Optimal patch departure; 1 patch density of known location

The travel time between patches differed among birds within each phase (ANOVA; $P<0.05$ ) and increased for each bird ( $t$-test; $P<0.01)$ between consecutive experiment phases (Table 1), except between phase 2 and 3 for Blue. The change in travel cost between patches was only small, however, as travel times only increased by approximately $4 \mathrm{~s}$ between phases 1 and 3 .

In Phase A, prey consumed by Al, Red, and Yellow did not differ $(P>0.05)$ from the number predicted by the marginal value theorem (Table 2). All other birds consumed more prey $(P<0.05)$ than predicted by the marginal value theorem.

In Phase $\mathrm{B}$ of this experiment, the predicted number of prey consumed from the patch increased only slightly (0.9-1.8 wheat grains) for each bird. The average number of prey consumed was not different $(P>0.05)$ from the predicted values in all but 2 of the birds (Blue and Yellow). As in Phase A, when observed values differed from predicted values, the birds consumed more food items from a patch than predicted.

In Phase $\mathrm{C}$ of Experiment 2, both Green and Yellow exhibited aberrant behavior during foraging and other activities, presumably because of the styrofoam backpack. Consequently, these birds were not included in the experiment. The number of prey consumed by all birds except Red did not differ $(P>0.05)$ from predicted values.

Experiment 3: Optimal patch departure; 2 patch densities of known location

The observed number of prey consumed from the both the low (100 prey) and high (150 prey) density patches did not differ $(P>0.05)$ from the predicted values in 4 of the 6 birds (Table 3). The birds consumed more prey than predicted by the marginal value theorem in all but one comparison when there was a difference between observed and predicted values.

Table 1. The travel time (mean \pm SE) between food patches for individual ruddy ducks in 3 phases of experiment 2

\begin{tabular}{lllllll}
\hline \multicolumn{7}{l}{ Travel time (s) } \\
\cline { 2 - 6 } & Al & Blue & Green & Fred & Red & Yellow \\
\hline Phase A & $23.6 \pm 0.1$ & $24.6 \pm 0.3$ & $24.4 \pm 0.4$ & $23.2 \pm 0.2$ & $23.9 \pm 0.3$ & $24.1 \pm 0.3$ \\
$n$ & 31 & 33 & 47 & 35 & 28 & 47 \\
$P$ & $*$ & $*$ & $*$ & $*$ & $*$ & $*$ \\
Phase B & $25.8 \pm 0.2$ & $27.3 \pm 0.1$ & $26.6 \pm 0.1$ & $26.0 \pm 0.4$ & $26.3 \pm 0.6$ & $26.9 \pm 0.5$ \\
$n$ & 21 & 34 & 33 & 37 & 39 & 42 \\
$P$ & $*$ & NS $* *$ & & $*$ & $*$ & \\
Phase C & $27.2 \pm 0.2$ & $27.7 \pm 0.3$ & a & $28.2 \pm 0.4$ & $28.4 \pm 0.5$ & a \\
$n$ & 25 & 24 & & 32 & 31 & \\
\hline
\end{tabular}

* Indicates adjacent values within columns are significantly different ( $t$-test $; P \leq 0.05$ )

** NS indicates no significant difference between adjacent values within a column $(t$-test $P>0.05)$

a Green and Red were not included in Phase $C$ because of aberrant behavior (see text) 
Table 2. The observed (mean $\pm S E$ ) and predicted (mean $\pm S E$ ) number of prey consumed by each ruddy duck from food patches in 3 phases of experiment 2 . Predicted values were derived with the marginal value theorem model. All patches contained 150 prey items

\begin{tabular}{lllllll}
\hline & Bird & & & & \\
\cline { 2 - 7 } & Al & Blue & Green & Fred & Red & Yellow \\
\hline Phase A $(n=10)$ & & & & & & \\
Observed & $38.4 \pm 6.2$ & $50.8 \pm 8.0$ & $53.2 \pm 6.4$ & $65.4 \pm 6.6$ & $49.8 \pm 7.4$ & $42.5 \pm 6.2$ \\
Predicted & $28.7 \pm 0.1$ & $28.9 \pm 0.1$ & $29.1 \pm 0.1$ & $28.4 \pm 0.1$ & $28.7 \pm 0.1$ & $28.9 \pm 0.1$ \\
$P$ & NS & $*$ & $*$ & $*$ & NS & NS \\
Phase B $(n=10)$ & & & & & & \\
Oserved & $30.7 \pm 5.1$ & $61.6 \pm 10.8$ & $38.4 \pm 6.6$ & $36.9 \pm 6.7$ & $32.7 \pm 12.6$ & $59.1 \pm 6.3$ \\
Predicted & $30.0 \pm 0.1$ & $30.4 \pm 0.1$ & $30.0 \pm 0.1$ & $30.0 \pm 0.1$ & $30.5 \pm 0.1$ & $30.2 \pm 0.1$ \\
$P$ & NS & $*$ & NS & NS & NS & $*$ \\
Phase C $(n=20)$ & & & & & & \\
Observed & $31.6 \pm 3.8$ & $27.8 \pm 4.0$ & a & $35.3 \pm 4.3$ & $45.4 \pm 3.7$ & a \\
Predicted & $31.3 \pm 0.1$ & $32.2 \pm 0.1$ & & $31.9 \pm 0.1$ & $32.1 \pm 0.1$ & \\
$P$ & NS & NS & & NS & $*$ & \\
\hline
\end{tabular}

* Indicates that observed and predicted values differ significantly $(P \leq 0.05)$

NS indicates that observed and predicted values do not differ significantly $(P>0.05)$

a Green and Red were not included in Phase $C$ because of aberrant behavior (see text)

Table 3. The observed (mean $\pm S E$ ) and predicted (mean $\pm S E$ ) number of prey consumed by individual ruddy ducks from 2 patches of different quality (100 and 150 prey). "Observed" results are averaged over 10 trials

\begin{tabular}{llllllll}
\hline & \multicolumn{3}{l}{ Tray 1-2 (100 prey) } & & \multicolumn{2}{c}{ Tray 4-2 (150 prey) } \\
\cline { 2 - 3 } \cline { 6 - 8 } Bird & Observed & $P$ & Predicted & & Observed & $P$ & Predicted \\
\hline Al & $24.3 \pm 4.4$ & NS & $18.1 \pm 0.1$ & & $49.4 \pm 5.7$ & $*$ & $77.5 \pm 0.1$ \\
Blue & $33.4 \pm 3.7$ & $*$ & $17.7 \pm 0.1$ & & $96.3 \pm 8.4$ & NS & $78.1 \pm 0.1$ \\
Green & $22.9 \pm 4.6$ & NS & $18.2 \pm 0.1$ & $63.9 \pm 9.4$ & NS & $77.7 \pm 0.1$ \\
Fred & $39.2 \pm 4.4$ & $*$ & $17.8 \pm 0.1$ & & $103.9 \pm 8.2$ & $*$ & $79.2 \pm 0.1$ \\
Red & $29.2 \pm 3.1$ & NS & $17.2 \pm 0.1$ & & $68.8 \pm 10.7$ & NS & $76.2 \pm 0.1$ \\
Yellow & $25.0 \pm 3.7$ & NS & $18.0 \pm 0.1$ & $78.4 \pm 7.5$ & NS & $79.1 \pm 0.1$ \\
\hline
\end{tabular}

* Indicates that observed and predicted values differ siguificantly $(P \leq 0.05)$

NS indicates that observed and predicted values do not differ significantly $(P>0.05)$

\section{Experiment 4: Optimal departure from a patch of unknown location}

In this experiment, the foraging birds made an average of $4.8 \pm 0.6$ (mean \pm SE) exploratory dives before locating a food patch. By having to make approximately 5 dives to find a food patch, the birds expended an average of 700 additional calories. All birds except Blue consumed significantly more prey from a patch in comparison with Phase $B$ of Experiment 2 (Table 4). When the extra costs of searching for a foraging site were accounted for in Equation 2, the optimal number of prey that should have been consumed from the food patch in this experiment did not differ $(P>0.05)$ from the number of prey consumed by all birds except Green (Table 5).

\section{Deviations from optimal energy intake}

Thus far, the results of all experiments have been expressed as the number of prey consumed averaged over several for-
Table 4. The number of prey (mean $\pm S E$ ) consumed by individual ruddy ducks from patches of known (omniscient) $(n=10)$ and unknown (nescient) $(n=5)$ locations. Each patch contained 150 prey when full

\begin{tabular}{llll}
\hline Bird & $\begin{array}{l}\text { Number } \\
\text { consumed } \\
\text { omniscient }\end{array}$ & $*$ & $\begin{array}{l}\text { Number } \\
\text { consumed } \\
\text { nescient }\end{array}$ \\
\hline Al & $30.7 \pm 5.1$ & $*$ & $80.4 \pm 11.0$ \\
Blue & $61.6 \pm 10.8$ & NS & $66.8 \pm 19.5$ \\
Green & $38.4 \pm 6.6$ & $*$ & $80.4 \pm 9.8$ \\
Fred & $36.9 \pm 6.7$ & $*$ & $80.8 \pm 9.7$ \\
Red & $32.7 \pm 12.6$ & $*$ & $89.2 \pm 19.0$ \\
Yellow & $59.1 \pm 6.3$ & $*$ & $96.6 \pm 12.7$ \\
\hline
\end{tabular}

* Indicates that values within a row differ significantly $(P \leq 0.05)$ NS indicates that values within a row do not differ significantly $(P>0.05)$

aging trials. Because the goal of the predator should be to maximize the average rate of net energy intake during a foraging bout (Charnov 1976), it is more appropriate to compare the rate of net energy intake obtained from a patch on a trial by trial basis with the optimal value predicted by the marginal value theorem. To calculate this, the cumulative number of prey consumed $(N)$ at the time the bird abandons the patch was used in the equation

$h(T)=150$ calories $* N$

to provide a measure of the energy intake, $h(T)$, at the time the bird abandons the patch. This value of $h(T)$, plus the amount of time spent foraging in the patch $(T)$ were used in Eq. (2) to calculate the average rate of net energy intake of the birds for each trial. This value was then subtracted from the maximum rate of net energy intake as predicted by the marginal value theorem. Of the 200 trials, $154(77 \%)$ resulted in a deviation of $30 \%$ or less from the optimal rate of net energy intake (Fig. 3). 
Table 5. The observed (mean \pm SE) and predicted (mean $\pm S E$ ) number of prey consumed from a patch containing 150 prey. The patch location was unknown to the foraging bird when it began the foraging bout. Results are based on 5 trials

\begin{tabular}{lrll}
\hline Bird & $\begin{array}{l}\text { Number } \\
\text { consumed } \\
\text { predicted }\end{array}$ & & $\begin{array}{l}\text { Number } \\
\text { consumed } \\
\text { observed }\end{array}$ \\
\hline Al & $95.6 \pm 0.1$ & NS & $80.4 \pm 11.0$ \\
Blue & $98.2 \pm 0.1$ & NS & $66.8 \pm 19.5$ \\
Green & $111.8 \pm 0.1$ & $*$ & $80.4 \pm 9.8$ \\
Fred & $105.5 \pm 0.1$ & NS & $80.8 \pm 9.7$ \\
Red & $99.6 \pm 0.1$ & NS & $89.2 \pm 19.0$ \\
Yellow & $101.2 \pm 0.1$ & NS & $96.6 \pm 12.7$ \\
\hline
\end{tabular}

* Indicates that observed and predicted values differ significantly $(P \leq 0.05)$

NS indicates that observed and predicted values do not differ significantly $(P>0.05)$

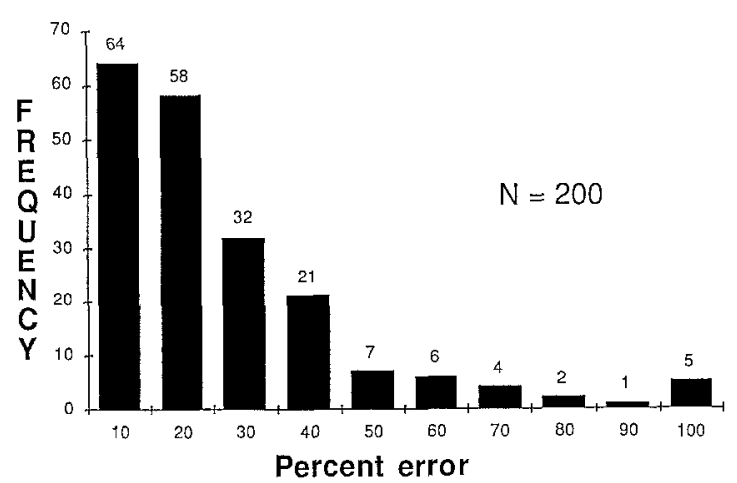

Fig. 3. Frequency distribution of the percent deviation from optimal rate of net energy intake observed by all birds in each trial of experiment $2(n=200)$. The deviations from optimal rate of net energy intake are grouped into categories of $10 \%$

Table 6. Individual average deviation (mean $\pm S E$ ) from optimal rate of net energy intake (calories/s) at the time of departure from food patches containing 150 prey

\begin{tabular}{ll}
\hline Bird & $\begin{array}{l}\text { Deviation from optimal rate } \\
\text { of net energy intake } \\
\text { (calories/s) }\end{array}$ \\
\hline Al & $1.7 \pm 2.6(n=50)$ \\
Blue & $11.7 \pm 2.3(n=50)$ \\
Green & $10.3 \pm 1.8(n=30)$ \\
Fred & $10.6 \pm 1.7(n=50)$ \\
Red & $6.1 \pm 2.6(n=50)$ \\
Yellow & $5.0 \pm 2.1 \quad(n=30)$ \\
\hline
\end{tabular}

Foraging efficiency varied among individuals. The average deviation from maximum rate of net energy intake by individuals in Experiment 2 (Table 6) indicated that $\mathrm{Al}$, Red, and Yellow abandoned patches when their rate of net energy intake was closer to maximum rate of net energy intake than the other 3 birds.

An examination of the relationship between rate of net energy intake and time spent foraging in the food patch (Fig. 4) indicated that the largest deviation from maximum rate of net energy intake occurred when a bird abandoned the patch earlier than predicted, or when the margin rate

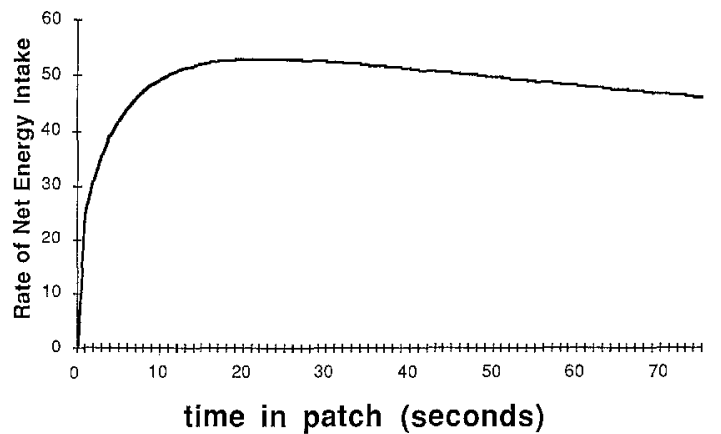

Fig. 4. The relation between rate of net energy intake and time spent foraging in a patch

of energy intake was still greater than the average rate of energy intake.

\section{Discussion}

The change in the rate of prey consumption with time spent foraging in a food patch exhibited by the ruddy ducks in Experiment 1 was consistent with a major assumption of Charnov's (1976) marginal value theorem: the energy intake increased at a decreasing rate with time spent foraging in the food patch. This assumption must be satisfied to use the foraging behavior of ruddy ducks as a quantitative test of the marginal value theorem.

In Experiment 2, the predicted values were not different from the actual number of prey consumed from the patch in 10 of 16 comparisons. Discrepancies in the number of prey consumed from a patch occurred because the birds stayed in a patch too long and consumed more prey than predicted. This error, however, resulted in a smaller deviation from optimal net energy intake than if the predator abandoned the patch too soon in the foraging bout, as shown by the net energy intake curve (Fig. 4). By staying in a patch too long, the ruddy ducks experienced only small deviations from maximum rate of net energy intake. To my knowledge, no previous investigator has examined the shape of the net energy intake curve to ascertain how much error in net energy intake is made by a predator that leaves a patch before of after the optimal number of prey has been consumed. In my experiments, the largest deviations from optimal prey intake occurred when the predator left the patch too early and, therefore, consumed too few prey.

As costs of traveling between patches increase, the average rate of energy intake from the environment will be lower (Charnov 1976). Consequently, a prediction of the marginal value theorem is that there should be a positive correlation between travel costs and number of prey consumed from a patch. This relationship was not observed in Experiment 2, probably because the energy costs of traveling between food patches were not increased sufficiently. To observe a significant increase in the number of prey consumed from a patch, the travel costs would have to be increased beyond the physical limitations of the aquarium I used for these experiments. The results of Experiment 4 , however, provided support to the travel-cost/preyconsumed relation predicted by the marginal value theorem. The increased costs of locating a randomly positioned food patch lowered the average rate of return in the environment sufficiently so that it was possible to detect an increase in the number of prey consumed compared to the numbers 
consumed in Experiment 2 when the birds knew the food patch location.

The ruddy duck's foraging behavior in an environment with patches of 2 densities provided additional quantitative and qualitative support for the predictions of the marginal value theorem. Again, when there were differences between the predicted and observed number of prey consumed, the birds stayed in the patches longer than predicted. This resulted in only small deviations from maximizing the rate of net energy intake. In 8 of the 12 comparisons, the number of prey consumed by the birds did not differ from the predicted number. Also, a comparison of the results of Experiment 3 with phase B of Experiment 2 provided qualitative support of the marginal value theorem. The foraging environment of Experiment 2 was of higher quality ( 2 patches of $150 \mathrm{prey} / \mathrm{tray})$ than that of Experiment 3 (1 patch of 100 prey/tray, 1 patch of 150 prey/tray). Thus, the average rate of return from the foraging environment of Experiment 2 was higher than that of Experiment 3 (Fig. 5). Consequently, even though the 150 prey/tray patches were of the same "quality" in both environments, the predator should have depleted the patches in the poor environment further than in the better environment (Charnov 1976; Krebs 1978). A comparison of the number of prey consumed by each bird in Experiment 2 (Table 2) with the number of prey consumed from Tray 4-2 in Experiment 3 (Table 3) provides quatitative and qualitative support for this prediction.

Individual variation in the ability to forage optimally has not been examined in detail in any natural or experimental studies. Individual variation in the ability to optimize foraging behavior was exhibited by the results of my experiments because 2 of the birds (Al and Red) foraged close to the predicted optimal values in all trials while the others exhibited varying degrees of sub-optimal behavior. Examination of the average deviation from optimal rate of net energy intake in individual foraging bouts from Experiment 2 provided additional support for this observation. When Al, Red, and Yellow abandoned the food patch, their average deviations from optimal rate of net energy intake varied between 1.7 and 6.1 calories/s, while the deviations of the other birds varied between 10.2 and 11.6 calories/s (maximum rate of net energy intake averaged 53.2 calories $/ \mathrm{s}$ ). The results of other studies where foraging behavior of individuals has been reported supports the notion that individual variation in foraging behavior exists (Smith and Dawkins 1971; Krebs et al. 1974; Smith and Sweatman 1974; Krebs et al. 1977). This is predictable because the basis for optimality theory is that there is a positive correlation between foraging efficiency (as defined by Sih 1982) and reproductive fitness. Therefore, scientists should expect to observe a range of foraging behaviors, with some individuals exhibiting smaller deviations from optimal behavior than others.

Animals are likely unable to perform the complex calculations necessary to determine the optimal energy intake from a patch of food (Oaten 1977; Krebs 1978; Kamil 1983). Rather, the decision to leave a patch is more likely based on some simple behavioral rule for patch departure, such as a constant amount of time spent in the patch, constant number of prey consumed from the patch, or a constant amount of time between the last prey item found and leaving the patch (i.e., giving-up time) (Iwasa et al. 1981; McNair 1982, 1983; Green 1984). These "rules of thumb"

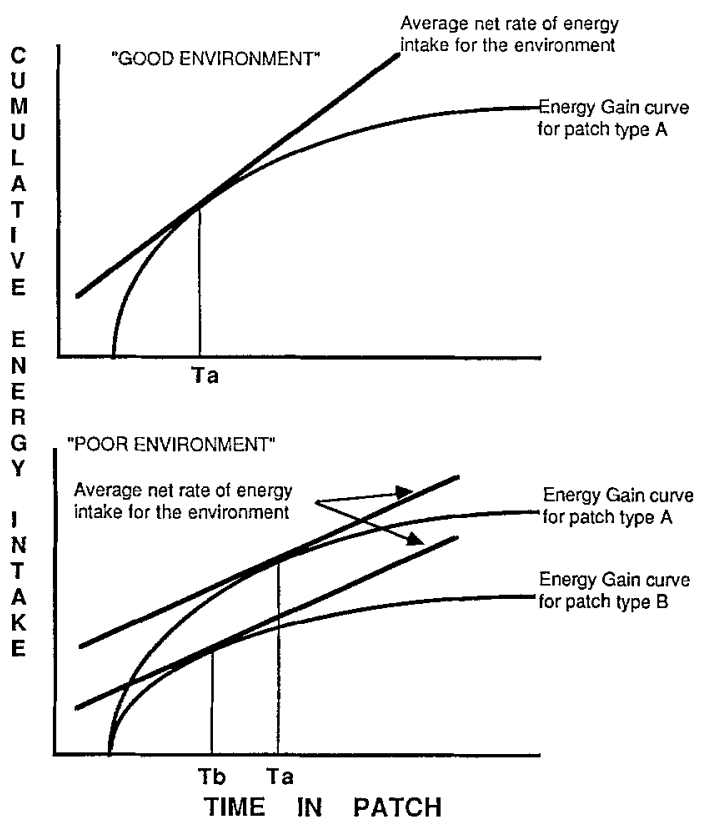

Fig. 5. Graphical depiction of the optimal time to leave a patch in 2 different habitat types. The "good" environment contains all patches of high quality (Type A). The "poor" environment contains some patches of high quality and some patches of low quality (Type B). The predator should leave a patch when the rate of energy gain from a patch falls below the average rate of energy gain from the environment. This occurs when the line representing the average rate of energy intake becomes tangent to the energy gain curve. From this relationship, the predator should stay in patch type A longer when foraging in the poor environment

have been shown to enable predators to make foraging "decisions" that are close to the optimal solution and also could be a factor contributing to the sub-optimal behavior observed in this study. Ruddy ducks do not use a time or number expectation giving-up rule, but the use of a constant giving-up time rule cannot be rejected (Tome 1986). Janetos and Cole (1981) reported that the difference between optimal net energy intake and the net energy obtained by following a simple behavioral rule may be quite small and may not be enough to affect reproductive fitness. Predators face numerous problems that may require optimal solutions. However, the optimal solution to an aggregation of problems may require some trade-offs that result in sub-optimal solutions to some individual problems.

The frequency at which foraging ruddy ducks encounter prey items probably affects how the birds interpret their current rate of prey intake from the patch. Deterministic models, such as the marginal value theorem, do not consider the effects that random variations in the encounter rate with prey have on a predator's evaluation of the patch quality. These models assume that the relationship between cumulative prey intake and cumulative time spent foraging can be explained by a smooth curve that monotonically increases at a decreasing rate. In real foraging situations, as well as in my experiments, this assumption is likely violated because the prey are encountered in random, discrete events, rather than in a deterministic manner. For example, consider that a predator has just entered a food patch but, because of random variation in the prey encounter rate, has found far fewer food items in a given period of time than would be predicted assuming a "deterministic" prey encounter rate at the density of that particular patch. If 
that predator were monitoring the rate of prey intake, it may leave the patch before the optimal number of prey was consumed because the predator's estimate of the rate of return from that particular patch would be too low. Although the predictions of the deterministic model tested in my experiments corresponded closely with the observed foraging behavior, the variation in number of prey consumed with time spent in the patch around the predicted, deterministic encounter rate (Fig. 3) suggests that the encounter rate with prey varied among trials.

There are stochastic models that account for the variability in prey encounter rate (e.g. Oaten 1977; Green 1980; McNamara 1982; Stephans and Charnov 1982). In general, they predict that a predator will spend more time in a patch than predicted by the marginal value theorem, presumably because some sampling time is necessary to determine the quality of the patch. Unfortunately, some of the variables (e.g., variation in the prey encounter rate) necessary to test the stochastic analogs of the marginal value theorem were not measurable in my experiments. Consequently, a comparison of the ruddy duck patch depletion results with the predictions of a stochastic model was impossible.

The foraging problem confronting wild ruddy ducks is probably more of a stochastic process than was simulated in my laboratory experiments. The patch densities vary widely (Tome 1981) and patch locations are ephemeral because of maturation of chironomid larvae, emergence of adults, and recolonization of the substrate by newly hatched larvae. Unfortunately, stochastic models are much more difficult to work with than their deterministic analogs, especially because many of the variables are difficult to measure. Deterministic models, however, may provide a good approximation of the foraging behavior of female ruddy ducks breeding in the wild because the birds probably have a good "idea" of the quality of the foraging environment in the wetlands on which they nest. Ruddy duck females rarely leave the general site of their nest (Tome 1984) and forage intensively within this area during the breeding season (52-66\% of daylight hours; Tome 1981); consequently, they likely are able to formulate an "idea" of the average rate of intake for that general feeding area. Because of the ruddy ducks' familiarity with the foraging environment, deterministic models may provide good approximations of the foraging "decisions" made by ruddy ducks in the wild.

The results of my experiments indicate that deterministic optimal foraging models can provide good quantitative predictions of the foraging decisions made by ruddy ducks in a controlled environment. The foraging behaviors of this species needs to be investigated further, however, to determine how variability in the prey encounter rate may affect foraging decisions concerning when to begin searching for a new, undepleted patch of prey.

Krebs et al. (1983) point out that the intent of optimal foraging models should not be to test whether animals are optimal; rather, these models should be used to examine whether the assumptions and criteria associated with the models are adequate to describe the animal's foraging behavior. With this idea in mind, it appears that the ruddy ducks in these experiments used some behavioral rule to attempt to maximize their rate of net energy intake.

Acknowledgements. I thank the many Webster Fellows and Assistants who assisted with the experiments and P. Ward and B.D.J.
Batt for their input into the study. Special thanks are due G.E. Belovsky, R.D. Drobney, B.A. Hazlett, D.L. Rabe, and D.S. White for their advice and constructive criticism. I also thank C.D. Ankney, R.T. Alisauskas, and 2 anonymous reviewers for their critiques of an earlier draft of this manuscript. This research was funded by the North American Wildlife Foundation through Delta Waterfowl and Wetlands Research Station.

\section{References}

Belovsky GE (1981) Food plant selection by a generalist herbivore: the moose. Ecol 62:1020-1030

Belovsky GE (1984) Summer diet optimization by beaver. Am Midl Nat 111:209-221

Brody S (1945) Bioenergetics and growth. Reinhold, New York

Charnov EL (1976) Optimal foraging: the marginal value theorem. Theor Pop Biol 9:129 136

Charnov EL, Orians GH, Hyatt K (1976) Ecological implications of resource depression. Am Nat 110:247-259

Cowie RJ (1977) Optimal foraging in great tits (Parus major). Nature 268:137-139

Efron B, Gong G (1983) A leisurely look at the boostrap, the jackknife, and cross-validation. Am Stat 37:36-48

Emlen JM (1966) The role of time and energy in food preference. Am Nat 100:611-617

Green RF (1980) Bayesian birds: a simple example of Oaten's stochastic model of optimal foraging. Theor Pop Biol $18: 244-256$

Green RF (1984) Stopping rules for optimal foragers. Am Nat $123: 30-40$

Iwasa Y, Higashi M, Yanamura N (1981) Prey distribution as a factor determining the choice of optimal foraging strategy. Am Nat 117:710-723

Janetos AC, Cole BJ (1981) Imperfectly optimal animals. Behav Ecol Sociobiol 9:203-209

Kamil AC (1983) Optimal foraging and the psychology of learning. Am Zool 23:291-302

Krebs JR (1978) Optimal foraging: decision rules for predators. In: Krebs JR, Davies NB (eds) Behavioural ecology: an evolutionary approach. Blackwell, Oxford, England, pp 23-63

Krebs JR, Cowie RJ (1976) Foraging strategies in birds. Ardea $64: 98-116$

Krebs JR, Ryan JC, Charnov EL (1974) Hunting by expectation or optimal foraging? A study of patch use by chickadees. Anim Behav 22:953-964

Krebs JR, Erichsen JT, Webber MI, Charnov EL (1977) Optimal prey selection in the great tit (Parus major). Anim Behav $25: 30-38$

Krebs JR, Stephans DW, Sutherland WJ (1983) Perspectives in optimal foraging. In: Brush AH, Clark GA (eds) Perspectives in ornithology. Cambridge Univ Press, Cambridge, pp 163-216

MacArthur RH, Pianka ER (1966) On optimal use of a patchy environment. Am Nat 100:603-609

McNair JN (1982) Optimal giving-up times and the marginal value theorem. Am Nat 119:511-529

McNair JN (1983) A class of patch-use strategies. Am Zool $23: 303-313$

McNamara J (1982) Optimal patch use in a stochastic environment. Theor Pop Biol 21:269-288

Oaten A (1977) Optimal foraging in patches: a case for stochasticity. Theor Pop Biol 12:263-285

Pyke GH (1984) Optimal foraging theory: a critical review. Ann Rev Ecol Syst 15:523-575

Pyke GH, Pulliam HR, Charnov EL (1977) Optimal foraging: a selective review of theory and tests. Q Rev Biol 52:137-154

Siegfried WR (1973) Summer food and feeding of the ruddy duck in Manitoba. Can J Zool 51:1293-1297

Sih A (1982) Optimal patch use: variation in selective pressure for efficient foraging. Am Nat 120:666-685

Smith JNM, Dawkins R (1971) The hunting behavior of individual 
great tits in relation to spatial variations in their food density. Anim Behav 19:695-706

Smith JNM, Sweatman HPA (1974) Food-searching behavior of titmice in patchy environments. Ecology 55:1216-1232

Stephans DW, Charnov EL (1982) Optimal foraging: some simple stochastic models. Behav Ecol Sociobiol 10:251-263

Tome MW (1981) Reproductive bioenergetics of female ruddy ducks in Manitoba. MS thesis University of Maine

Tome MW (1984) Changes in nutrient reserves and organ size of female ruddy ducks breeding in Manitoba. Auk 101:830-837

Tome MW (1986) Foraging behavior of ruddy ducks: a test of optimal foraging theory. $\mathrm{Ph} \mathrm{D}$ dissertation. University of Michigan

Ward P, Batt BDJ (1973) Propagation of captive waterfowl: the
Delta Waterfowl Research Station system. Wildl Mgmt Inst, Washington DC

Woakes AJ, Butler PJ (1983) Swimming and diving in tufted ducks, Aythya fuligula, with particular reference to heart rate and gas exchange. J Exp Biol 107:311-329

Wooley JB, Owen RB Jr (1978) Energy costs of activity and daily energy expenditure in the black duck. J Wildl Manage $42: 739-745$

Zar JH (1974) Biostatistical analysis. Prentice-Hall Inc, Englewood Cliffs NJ

Received December 2, 1987 